\title{
Characteristics of metal-tolerant plant growth-promoting yeast (Cryptococcus sp. NSE1) and its influence on Cd hyperaccumulator Sedum plumbizincicola
}

\author{
Wuxing Liu ${ }^{1}$ - Beibei Wang ${ }^{1,2}$ - Qingling Wang ${ }^{1}$ Jinyu Hou ${ }^{1,2}$ - Longhua Wu ${ }^{1}$. \\ Jennifer L. Wood ${ }^{3}$. Yongming Luo ${ }^{1,4}$ • Ashley E. Franks ${ }^{3}$
}

Received: 20 February 2016 / Accepted: 5 June 2016 / Published online: 15 June 2016

(C) Springer-Verlag Berlin Heidelberg 2016

\begin{abstract}
Plant growth-promoting yeasts are often over looked as a mechanism to improve phytoremediation of heavy metals. In this study, Cryptococcus sp. NSE1, a Cd-tolerant yeast with plant growth capabilities, was isolated from the rhizosphere of the heavy metal hyperaccumulator Sedum plumbizincicola. The yeast exhibited strong tolerance to a range of heavy metals including $\mathrm{Cd}, \mathrm{Cu}$, and $\mathrm{Zn}$ on plate assays. The adsorption rate $\mathrm{Cd}, \mathrm{Cu}, \mathrm{Zn}$ by NSE1 was 26.1, 13.2 , and $25.2 \%$, respectively. Irregular spines were formed on the surface of NSE1 when grown in MSM medium supplemented with $200 \mathrm{mg} \mathrm{L}^{-1} \mathrm{Cd}$. NSE1 was capable of utilizing 1-aminocyclopropane-1-carboxylate (ACC) as a sole nitrogen source and was capable of solubilization of inorganic phosphate at rates of $195.2 \mathrm{mg} \mathrm{L}^{-1}$. Field experiments demonstrated that NSE1 increased phytoremediation by increasing the biomass of Cd hyperaccumulator S. plumbizincicola $(46 \%, p<0.05)$ during phytoremediation. Overall, $\mathrm{Cd}$
\end{abstract}

Responsible editor: Elena Maestri

Electronic supplementary material The online version of this article (doi:10.1007/s11356-016-7041-2) contains supplementary material, which is available to authorized users.

Wuxing Liu

liuwuxin@issas.ac.cn

1 Key Laboratory of Soil Environment and Pollution Remediation, Institute of Soil Science, Chinese Academy of Sciences, Nanjing 210008, China

2 University of Chinese Academy of Sciences, Beijing 100049, China

3 Department of Physiology, Anatomy and Microbiology, La Trobe University, Melbourne, VIC 3086, Australia

4 Institute of Coastal Zone Research, Chinese Academy of Sciences, Yantai 264003, China accumulation by S. plumbizincicola was increased from 19.6 to $31.1 \mathrm{mg} \mathrm{m}^{-2}$ though no difference in the concentration of $\mathrm{Cd}$ in the shoot biomass was observed between NSE1 and control. A Cd accumulation ratio of $38.0 \%$ for NSE1 and $17.2 \%$ for control was observed. The HCl-extractable $\mathrm{Cd}$ and $\mathrm{CaCl}_{2}$-extractable $\mathrm{Cd}$ concentration in the soil of the NSE1 treatment were reduced by 39.2 and $29.5 \%$, respectively. Community-level physiology profiling, assessed using Biolog Eco plates, indicated functional changes to the rhizosphere community inoculated with NSE1 by average well color development (AWCD) and measurement of richness (diversity). Values of Shannon-Weiner index, Simpson index, and McIntosh index showed a slight but no significant increases. These results indicate that inoculation of NSE1 could increase the shoot biomass of S. plumbizincicola, enhance the $\mathrm{Cd}$ accumulation in S. plumbizincicola, and decrease the available heavy metal content in soils significantly without overall significant changes to the microbial community.

Keywords Cd-contaminated soil · Phytoremediation · Cryptococcus sp. · Plant growth promoting $\cdot$ Microbial community

\section{Introduction}

Soil contamination by heavy metals has increased considerably during the last few decades. Among heavy metals, cadmium $(\mathrm{Cd})$ is one of the most toxic contaminants due to its high mobility and toxicity in soils (Guo et al. 2010). Cd is readily taken up by plants and results in growth inhibition, alterations in nutrient uptake, and activated oxygen metabolism, chlorosis, and even plant death (Sandalio et al. 2001). Cd may affect a wide range of living organisms, including humans, through accumulation within the food chain. $\mathrm{Cd}$ is 
a carcinogen and acute exposure may lead to flu-like symptoms, renal tube dysfunction, softening of bones, kidney failures, and pain (Żukowska and Biziuk 2008). This pain associated with the mass cadmium poisoning in the Toyama Prefecture of Japan in 1912 led to the name itai-itai disease (it hurts-it hurts disease) (Sato et al. 2010). Cd contamination therefore must be removed due to concerns for both environment quality and human health.

Techniques for the remediation of heavy metal-contaminated soils include immobilization and phytoremediation. Immobilization can reduce the mobility and bioavailability of heavy metals through addition of remediation agents to contaminated soils. Researchers have reported that amendment with dithiocarbamate chitosan (DTC-CTS) is effective in immobilizing $\mathrm{Cd}$ and mitigating accumulation in plants (Yin et al. 2015), and thus potentially alleviate the toxicity of $\mathrm{Cd}$ to plants. Phytoremediation is advantageous as it physically removes the heavy metal contaminant from the soil through accumulation in plant biomass. Phytoextraction suffers from several main limitations such as the low biomass of the hyperaccumulators and low bioavailability of heavy metals (Chen et al. 2010). The use of plant growth-promoting rhizobacteria (PGPR) to improve phytoremediation was first proposed by Kloepper et al. (1980) and has since been reported to abate heavy metal stress, promote biomass production, and improve phytoremediation in contaminated soils (Kumar et al. 2015; Marques et al. 2013).

Previous research into the use of PGPR has focused on bacteria (Vessey 2003) or mycorrhizal fungi (Johansson et al. 2004), while relatively fewer attempts were made to use yeasts as plant growth promoter. Yeasts are unicellular fungi which can proliferate rapidly on simple carbohydrates (Mukherjee and Sen 2015). Yeasts have shown adaption to environmental niches including an ability to colonize the rhizosphere in association with plant roots (Amprayn et al. 2012; Botha 2011; Cloete et al. 2009). A diverse range of yeasts have been reported to exhibit plant growth-promoting characteristics, including phosphate solubilization (Alonso et al. 2008; Falih and Wainwright 1995), siderophore production (Sansone et al. 2005), phytohormone production (Nassar et al. 2005), pathogen inhibition (El-Tarabily and Sivasithamparam 2006; Sansone et al. 2005), $\mathrm{N}$ and S oxidation (Botha 2011) and stimulation of mycorrhizal-root colonization (Alonso et al. 2008). In addition, several yeasts have received considerable attention and have been applied for the management of heavy metal pollution as their strong resistance and specific metal sorption capacities toward a broad range of heavy metals (Bankar et al. 2012). Therefore, yeasts may be able to play a potential role in the enhancement of plant growth under heavy metal stress.

Sedum plumbizincicola is a Cd hyperaccumulator plant noted for its remarkable $\mathrm{Cd}$ extraction capacity from polluted soils (Wu et al. 2008). However, the potential effect of exogenous yeast with plant growth-promoting (PGP) abilities on the growth of $S$. plumbizincicola, Cd uptake, and changes in the microbial diversity of the rhizosphere has not been previously studied. Therefore, to improve our understanding of the potential for exogenous yeast and to improve $\mathrm{Cd}$ phytoremediation by S. plumbizincicola on heavy metalcontaminated farmland, we (1) isolated a metal-tolerant plant growth-promoting yeast, (2) evaluated PGP characteristics of the isolated strain, (3) observe the effect of the yeast inoculant on Cd hyperaccumulator $S$. plumbizincicola growth and absorption of $\mathrm{Cd}$, and (4) examined the influence of yeast inoculation on the functional diversity indices and activity of the soil microbial community after phytoremediation.

\section{Materials and methods}

\section{Isolation of Cd-tolerant strain}

Fresh root samples $(1 \mathrm{~g})$ were taken from $S$. arboretum that had been grown for 120 days in $20 \mathrm{mg} \mathrm{kg}^{-1} \mathrm{Cd}$ contaminated soils in a glasshouse. Roots were washed in sterile water before homogenization in $1 \mathrm{~mL}$ of sterile water using sterile mortar and pestle. Serial dilutions of this suspension were prepared $\left(10^{-1}-10^{-3}\right)$ and $100 \mu \mathrm{L}$ was spread onto the SMN medium agar (Belimov et al. 2001) supplemented with $20 \mathrm{mg} \mathrm{L}^{-1}$ of $\mathrm{CdCl}_{2}$. The SMN medium's $\mathrm{pH}$ was adjusted to 7.0 before autoclaving and ACC $\left(0.5 \mathrm{~g} \mathrm{~L}^{-1}\right)$ was added as the sole nitrogen source after filter sterilization. After incubation for 7 days at $30{ }^{\circ} \mathrm{C}$, individual colonies of distinct morphology were isolated through streak plating on the YPD medium (1\% yeast extract, $2 \%$ peptone, $2 \%$ dextrose) supplemented with $20 \mathrm{mg} \mathrm{L}^{-1}$ of $\mathrm{CdCl}_{2}$. The yeast was selected according to the morphology and microscopic examination.

\section{Identification of isolated yeast strain}

\section{DNA extraction}

DNA was extracted from yeast cells using a detergent and mechanical-based disruption technique to overcome the more robust cell wall of eukaryotes. The method was adapted from Cheng and Jiang (2006). Briefly, cells were grown overnight in $10 \mathrm{~mL}$ of $\mathrm{LB}$ then transferred in $1-\mathrm{mL}$ allocates to an

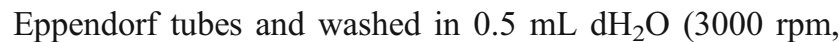
$3 \mathrm{~min})$. Cells were then re-pelleted and combined with $300 \mu \mathrm{L}$ of acid-washed glass beads (Sigma), $200 \mu \mathrm{L}$ of detergent lysis buffer ( $\%$ Triton X-100, $1 \%$ SDS, $100 \mathrm{mM} \mathrm{NaCl}$, $10 \mathrm{mM}$ Tris- $\mathrm{HCl} \mathrm{pH} 8,1 \mathrm{mM}$ EDTA), and $200 \mu \mathrm{L} \mathrm{1:1}$ phenol/chloroform (bottom layer) for DNA extraction. 
Eppendorf tubes were sealed with parafilm and vortexed for 3-4 min on a multi-head vortex at maximum speed. TE $(200 \mu \mathrm{L})(10 \mathrm{mM}$ Tris $\mathrm{pH} 8,1 \mathrm{mM}$ EDTA $)$ was added and the samples centrifuged (13,000 rpm, $5 \mathrm{~min})$. The aqueous layer was transferred to a fresh Eppendorf tube and $1 \mathrm{~mL}$ of ice cold $100 \%$ ethyl alcohol $(\mathrm{EtOH})$ was added. Samples were mixed by inversion and the DNA pelleted (13,000 rpm, $\left.2 \mathrm{~min}, 4^{\circ} \mathrm{C}\right)$. The supernatant was discarded and the pellet was resuspended in $400 \mu \mathrm{L}$ TE $(\mathrm{pH} 8)$ with $3 \mu \mathrm{L}$ of RNase $\left(10 \mathrm{mg} \mathrm{mL}^{-1}\right.$ Promega) and incubated for $5 \mathrm{~min}$ at $37^{\circ} \mathrm{C}$. DNA was precipitated via the addition of $10 \mu \mathrm{L}$ of $4 \mathrm{M}$ ammonium acetate and $1 \mathrm{~mL}$ of ice cold $100 \%$ EtOH. Samples were mixed by inversion and then centrifuged $\left(13,000 \mathrm{rpm}, 2 \mathrm{~min}, 4{ }^{\circ} \mathrm{C}\right)$. The supernatant was decanted and the pellet air-dried before being resuspended in $50 \mu \mathrm{L} \mathrm{TE}(\mathrm{pH} 8)$ and stored at $-20{ }^{\circ} \mathrm{C}$ for future use.

\section{PCR of 26S rRNA genes}

Polymerase chain reaction (PCR) procedures were adapted from Sambrook and Russell (2001). Primers NL1 (5'GCATATCAATAAGCGGAGGAAAAG) and NL4 (5'GGTCCGTGTTTCAAGACGG) (Kurtzman and Robnett 1997) were used to amplify the D1/D2 variable domain at the $5^{\prime}$ end of the 28S rRNA gene from the gDNA extract.

Amplifications were carried out in $20-\mu \mathrm{L}$ reaction mixes on a CFX Connect Real-Time PCR Detection System (BioRad). The reaction mixture utilized reagents and buffers supplied by Qiagen and contained $2 \mu \mathrm{L}$ of $10 \times$ PCR buffer, 4- $\mu \mathrm{L}$ of Q solution, $0.4 \mu \mathrm{L} \mathrm{MgCl}_{2}$ (25 mM), 0.5 $\mu \mathrm{L}$ of Taq DNA polymerase, 9.1 $\mu \mathrm{L}$ $\mathrm{dH}_{2} \mathrm{O}, 1 \mu \mathrm{L}$ of each primer $(10 \mathrm{mM}), 1 \mu \mathrm{L}$ dNTP mix (10 mM), and $1 \mu \mathrm{L}$ of gDNA (50 ng) template. Cycle settings used for amplification were as follows: initial denaturation $\left(95{ }^{\circ} \mathrm{C}\right.$ for $\left.180 \mathrm{~s}\right)$ followed by 30 cycles of denaturation (95 for $60 \mathrm{~s}$ ), annealing $\left(52{ }^{\circ} \mathrm{C}\right.$ for $45 \mathrm{~s}$ ), and extensions of $72{ }^{\circ} \mathrm{C}$ for $120 \mathrm{~s}$ before a final extension $\left(72{ }^{\circ} \mathrm{C}\right.$ for $300 \mathrm{~s}$ ).

Amplified replicate reaction mixes were pooled for purification and analyzed by DNA electrophoresis (1\% Agarose gel with $0.1 \mu \mathrm{L} \mathrm{mL}^{-1}$ Syber Safe, run at $100 \mathrm{~V}$ for $45 \mathrm{~min}$ ). The amplified product was excised from the gel, cleaned up using the WIZARD® SV Gel \& PCR Cleanup system (Promega), and sequenced by the Australian Genome Research Facility (AGRF) via Sanger sequencing using the AB 3730xl platform. Four replicate $20-\mu \mathrm{L}$ reactions were used for each sequencing run. Primers for these reactions were the external primers (NL1 and NL2) as well as primers internal to the sequencing region: NL2A (5'-CTT GTT CGC TAT CGG TCT C) and NL3A (5'-GAG ACC GAT AGC GAA CAA G) (Kurtzman and Robnett 1997).

\section{Characteristics of the isolate strain}

Heavy metal tolerance and biosorption experiment

Minimal inhibitory concentrations (MICs) for each metal were determined by the plate dilution method (Malik and Jaiswal 2000). In order to avoid precipitation of heavy metals, tolerance to heavy metals was tested in sucrose-minimal salts low phosphate (SLP) medium (Jiang et al. 2008) supplemented with the following metal cations: $\mathrm{Cd}^{2+}\left(\mathrm{CdCl}_{2}\right), \mathrm{Cu}^{2+}$ $\left(\mathrm{CuCl}_{2}\right)$, and $\mathrm{Zn}^{2+}\left(\mathrm{ZnCl}_{2}\right)$ at a range of concentrations $(0$ $\left.3000 \mathrm{mg} \mathrm{L}^{-1}\right)$. The SLP agar plates without metals were used as controls. The experiments were carried out in triplicate. Cultures were incubated at $28^{\circ} \mathrm{C}$ for 7 days. The absorptivity to heavy metals $(\mathrm{Cu}, \mathrm{Zn}, \mathrm{Cd})$ of NSE1 was determined in the YPD medium supplemented with $100 \mathrm{mg} \mathrm{L}^{-1}$ of heavy metals.

\section{Effects on the morphology of cadmium}

The Cd-tolerant PGP yeast NSE1 was inoculated in mineral salt medium (MSM) supplemented with $200 \mathrm{mg} \mathrm{L}^{-1} \mathrm{Cd}$ and the control without $\mathrm{Cd}$. After 3 days, the microbial morphology was observed by scanning electron microscope (SEM) according to Staniszewska et al. (2013).

\section{Determination of yeast phosphorus solubilizing}

A modified PVK medium was used for all experiments unless otherwise stated, containing ( $\mathrm{g} \mathrm{L}^{-1}$ in distilled water) glucose 10.0, $\left(\mathrm{NH}_{4}\right)_{2} \mathrm{SO}_{4} 0.5, \mathrm{NaCl} 0.2, \mathrm{MgSO}_{4} 0.1, \mathrm{KCl} 0.2$, yeast extract $0.5, \mathrm{MnSO}_{4}$ 0.002, and $\mathrm{FeSO}_{4}$ 0.002. The pH was adjusted to 7.0 for all experiments before autoclaving. Phosphate $\left(\mathrm{PO}_{4}{ }^{3-}\right)$ was added at $5.0 \mathrm{~g} \mathrm{~L}^{-1}$ as $\mathrm{Ca}_{3}\left(\mathrm{PO}_{4}\right)_{2}$. All experiments were conducted with triplicate sample flasks for each time sample, with $25 \mathrm{~mL}$ of liquid growth media in 100 -mL flasks. Flasks were incubated aerobically with shaking $(160 \mathrm{rpm})$ for 6 days at $28^{\circ} \mathrm{C}$. Every $12 \mathrm{~h}, 300 \mu \mathrm{L}$ of culture suspension was taken for $\mathrm{OD}_{600 \mathrm{~nm}}$ determination. The remainder of the sample was centrifuged at $8000 \mathrm{rpm}$ for $10 \mathrm{~min}$, the $\mathrm{pH}$ was determined potentiometrically, and soluble $\mathrm{P}$ in the supernatant was quantified by the ammonium molybdate spectrophotometric method as described by Payne (1994).

\section{Field experiments}

\section{Microbial inoculum preparation}

Field inoculum was prepared by mixing NSE1 with sterilized wheat bran as an inoculation matrix. In brief, NSE1 was grown in a fermenter (East Biotech Equipment and Technology Co., Ltd.) containing YBD media (4 L), $28^{\circ} \mathrm{C}$, 
$180 \mathrm{r} \mathrm{min}^{-1}$, and $4 \mathrm{~L} \mathrm{~min}^{-1}$ of air flow, to a density of $10^{8}$ colony-forming units (CFUs) $\mathrm{mL}^{-1}$ then mixed with wheat bran in ratio of $2: 3$ before storage at $4{ }^{\circ} \mathrm{C}$ and application into the field. Sterilized NSE1 mixed with wheat bran was utilized as a negative control.

\section{Site selection and experimental design}

Field experiments were conducted at Xiangtan city $\left(27^{\circ} 52^{\prime} \mathrm{N}\right.$ and $112^{\circ} 53^{\prime} \mathrm{E}$ ) in Hunan province, China, to evaluate the effects of NSE1 inoculation on Cd hyperaccumulator S. plumbizincicola biomass and Cd uptake. Field experiments were carried out from April 13 to July 16, 2014. Field sites are in a temperate zone with a moist sub-tropical monsoon climate with $1640-1700 \mathrm{~h}$ of annual average sunshine. The average annual temperature and precipitation are $16.7-17.4{ }^{\circ} \mathrm{C}$ and $1200 \sim 1500 \mathrm{~mm}$, respectively. The basic soil properties at the start of the experiment were as follows: $\mathrm{pH}$ (1:2.5 soil/water) 4.53 , organic matter $40.2 \mathrm{~g} \mathrm{~kg}^{-1}$, total $\mathrm{K} 10.4 \mathrm{~g} \mathrm{~kg}^{-1}$, total P $0.51 \mathrm{~g} \mathrm{~kg}^{-1}$, available $\mathrm{P} 15.7 \mathrm{mg} \mathrm{kg}^{-1}$, available $\mathrm{K}$ $162 \mathrm{mg} \mathrm{kg}^{-1}$, total $\mathrm{Cd} 0.70 \mathrm{mg} \mathrm{kg}^{-1}$ (determined using routine methods ( $\mathrm{Lu} \mathrm{1999))}$.

Stem cuttings $(10 \mathrm{~cm})$ of the $\mathrm{Cd}$ hyperaccumulator S. plumbizincicola were prepared from the middle section of 1 -year-old plant shoots. The experiment was conducted in a split-plot design with three replications. The unit sub-plot size was $1.6 \times 3.1 \mathrm{~m}$ about $5 \mathrm{~m}^{2}$ and every adjacent plot was separated by a gap in $30 \mathrm{~cm}$. Plant spacing and row spacing in each sub-plot were both $20 \mathrm{~cm}$ with 105 S. plumbizincicola cuttings planted in every area. Approximately $3 \mathrm{~g}$ of microbial inoculum was added to each plant in the soil around the plant stem.

\section{Sampling and analyses of heavy metal}

At harvest, the plants were cut at the soil surface and washed with de-ionized water before being oven-dried $\left(105^{\circ} \mathrm{C}\right.$ for $0.5 \mathrm{~h}$ and subsequently at $85^{\circ} \mathrm{C}$ for 5-6 h). Dry plant samples $(\sim 0.5 \mathrm{~g})$ were digested using a mixture of $6 \mathrm{~mL} \mathrm{HNO}_{3}$ and $4 \mathrm{~mL} \mathrm{HClO}_{4}$, and concentrations of $\mathrm{Cd}$ was determined using flame atomic absorption spectrometry (AAS, Varian SpectrAA 220 FS). The soil samples from the plant root in each pot were collected; stored at $4{ }^{\circ} \mathrm{C}$; and partly were air dried, ground, and passed through a 60- and 100-mesh sieve. Soil sub-samples were digested with $5 \mathrm{ml} \mathrm{HNO}_{3}$ and $5 \mathrm{~mL}$ $\mathrm{HCl}$. The concentration of total $\mathrm{Cd}$ was measured with a graphite furnace atomic absorption spectrophotometry (GFAAS) after dilution. The measurements of $\mathrm{HCl}$-extractable and $\mathrm{CaCl}_{2}$-extractable $\mathrm{Cd}$ in soil $(\mathrm{pH}<7.0)$ were obtained by equilibrating the soil in $0.1 \mathrm{M} \mathrm{HCl}$ and $0.01 \mathrm{M} \mathrm{CaCl}_{2}$ solution, respectively, and were finally analyzed by AAS.

\section{Microbial CLPP analysis}

The microbial community function was analyzed using Biolog $\mathrm{Eco}^{\mathrm{TM}}$ plates adapted from Bundy et al. (2004). An aliquot of $10 \mathrm{~g}$ fresh soil was shaken with $100 \mathrm{~mL}$ of autoclave-sterilized saline solution $(0.85 \% \mathrm{NaCl}, w / v)$ for $60 \mathrm{~min}$ and then aliquots of $10^{-3}$ dilutions were used to inoculate ECO plates $\left(150 \mu \mathrm{L}\right.$ per well) and incubated at $25{ }^{\circ} \mathrm{C}$. The plates were read every $12 \mathrm{~h}\left(\mathrm{OD}_{590 \mathrm{~nm}}\right)$ over $192 \mathrm{~h}$ using a BIOLOG automated plate reader. All wells were blanked to the control wells. For the BIOLOG data, average well color development (AWCD) was calculated as described by Garland and Mills (1991). Microbial diversity indices, such as Shannon-Weiner index (Spellerberg and Fedor 2003), McIntosh index, Simpson index, richness and substrate evenness, were calculated according to Gomez et al. (2006).

\section{Statistical analysis}

Statistical analysis was conducted with SPSS 17.0 software. Duncan's multiple range tests were used to compare the means of treatments; variability in the data was expressed as the standard errors. All analyses were performed at the $p<0.05$ level.

\section{Results}

\section{Identification and characteristics of the yeast rhizosphere isolate NSE1}

A Cd-tolerant isolate NSE1, which could use ACC as the sole nitrogen source, was obtained from the root of the $\mathrm{Cd}$ hyperaccumulator Carpobrotus rossii grown in a $\mathrm{Cd}$ contaminated soil. The isolate NSE1 was preliminarily identified as Cryptococcus sp. by 26S rRNA gene sequence homology (99\% similarity) (GenBank accession number 1859883) (Fig S1). NSE1 showed strong tolerance to the heavy metals $\mathrm{Cd}, \mathrm{Zn}$, and $\mathrm{Cu}$ with MICs of $1000 \mathrm{mg} \mathrm{L}^{-1}$ $\mathrm{Cd}, 3000 \mathrm{mg} \mathrm{L}^{-1} \mathrm{Cu}$, and $3000 \mathrm{mg} \mathrm{L}^{-1} \mathrm{Zn}$ on plate assays (Table 1). The adsorption rate of NSE1 to $\mathrm{Cd}, \mathrm{Cu}$, and $\mathrm{Zn}$ and were $26.1,13.2$, and $25.2 \%$, respectively (Table 1 ).

Distinct morphological changes of NSE1 in MSM supplemented with $200 \mathrm{mg} \mathrm{L}^{-1} \mathrm{Cd}$ was observed (Fig. 1). Some irregular spines were formed on the surface compared with the control treatment, which may be polysaccharide substances, and play a key role in the chelation and absorption $\mathrm{Cd}$ in yeast.

\section{Determination of yeast phosphorus solubilizing}

The growth of NSE1 in the PVK medium was associated with an accumulation of soluble $\mathrm{P}$ (Fig. 2 and Fig. 3). $\mathrm{P}$ in the 
Table 1 Minimal inhibitory concentrations (MICs) and adsorptivity to heavy metals of NSE1

\begin{tabular}{lccc}
\hline & $\mathrm{Cd}$ & $\mathrm{Cu}$ & $\mathrm{Zn}$ \\
\hline MICs $\left(\mathrm{mg} \mathrm{L}^{-1}\right)$ & 1000 & 3000 & 3000 \\
Adsorption rate (\%) & 26.1 & 13.2 & 25.2 \\
\hline
\end{tabular}

medium increased over time, while the medium's pH (Fig. 2) quickly decreased from 7.0 to 5.1 within the first $36 \mathrm{~h}$, and finally dropped to 4.5 at the end of the experiment. However, there is a slight fluctuation at $84 \mathrm{~h}(\mathrm{pH} 4.9)$. Soluble $\mathrm{P}$ in the solution did not change according to a sigmoid curve but steadily increased over time. In the first $72 \mathrm{~h}$, soluble P reached $105.4 \mathrm{mg} \mathrm{L}^{-1}$ at $72 \mathrm{~h}$ but was followed with a sudden decrease at $84 \mathrm{~h}\left(40.8 \mathrm{mg} \mathrm{L}^{-1}\right)$. According to the experiment, the solubilizing ability of NSE1 can reach $195.2 \mathrm{mg} \mathrm{L}^{-1}$, which is accompanied by a significant drop in $\mathrm{pH}$ (to 5.1) from an initial $\mathrm{pH}$ of 7.0 after $72 \mathrm{~h}$.

\section{Effects of microbial inoculation on S. plumbizincicola biomass and Cd extraction}

Compared with the control group, the dry biomass yield of the inoculated treatment (NSE1) was increased significantly $(p<0.05)$ by $46 \%$ and up to $308 \mathrm{~g} \mathrm{~m}^{-2}$ (Table 2). While the $\mathrm{Cd}$ concentration in shoots of NSE1 treatment was not significantly different from that of the control, the total Cadmium extracted (the shoot weight $\times \mathrm{Cd}$ concentration) rose significantly from 19.6 to $31.1 \mathrm{mg} \mathrm{m}^{-2}$ (Table 2), an increase of $58.8 \%$. This demonstrated that an increase in plant biomass is beneficial to total heavy metal extraction.

Total Cd in the soil treatment inoculated with NSE1 $\left(0.315 \mathrm{mg} \mathrm{kg}^{-1}\right)$ was lower than the control group $\left(0.438 \mathrm{mg} \mathrm{kg}^{-1}\right)$. S. plumbizincicola in the inoculated treatment (NSE1) and the control removed about 38.0 and $17.2 \%$ $\mathrm{Cd}$, respectively, in 0.2-m tillage layer of soil bulk with a bulk density of $1.3 \mathrm{~g} \mathrm{~cm}^{-3}$. Furthermore, the soil HCl-extractable $\mathrm{Cd}$ and $\mathrm{CaCl}_{2}$-extractable concentration in NSE1 treatments

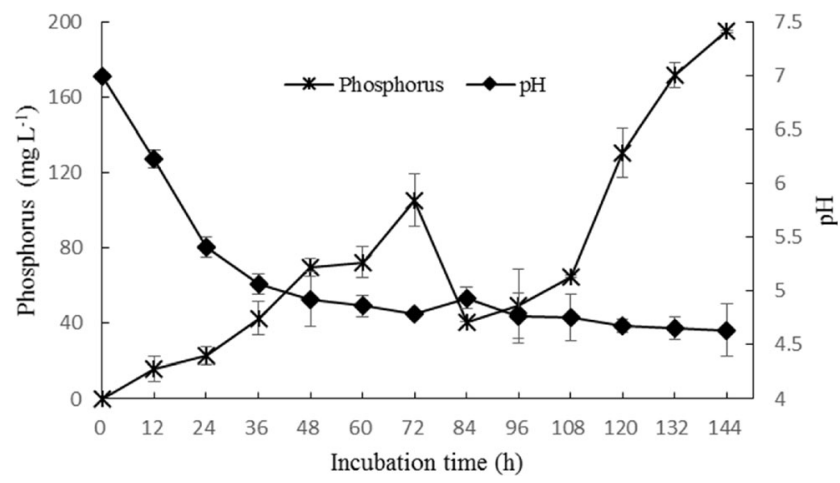

Fig. 2 Phosphorus concentration in culture solution with $\mathrm{Ca}_{3}\left(\mathrm{PO}_{4}\right)_{2}$ and $\mathrm{pH}$ varied with incubation time

were reduced by 39.2 and $29.5 \%$, respectively, compared to the control. It can be concluded that the inoculation of yeast NSE1 could significantly enhance the accumulation of heavy metals cadmium in hyperaccumulator and simultaneously decrease the available heavy metal content in soils $(p<0.05)$.

\section{Analysis of microbial community function}

The activity of soil microbial communities evaluated by AWCD was always higher in the inoculated soil than that in the control plot (Fig. 4). No differences in the AWCD was observed within the first $24 \mathrm{~h}$ but increased afterwards, and the AWCD of NSE1 was higher than that of the control with the increase of incubation time. A single time point absorbance at $144 \mathrm{~h}$, when the optical density did not increase for the highest number of wells over all plates, was used to calculate diversity indices of the microbial community. The values of Shannon-Weiner index, Simpson index, McIntosh index, and richness were shown in Table 3; the value of richness (calculated using an OD of 0.25 as threshold for positive response (Garland 1997)) for NSE1 was 24.5, which was significantly $(p<0.05)$ greater than 20.5 for the control. The Shannon-Weiner index (provided information on the distribution of carbon source utilization and potential metabolic diversity (Gomez et al. 2006; Garland 1997)), McIntosh index

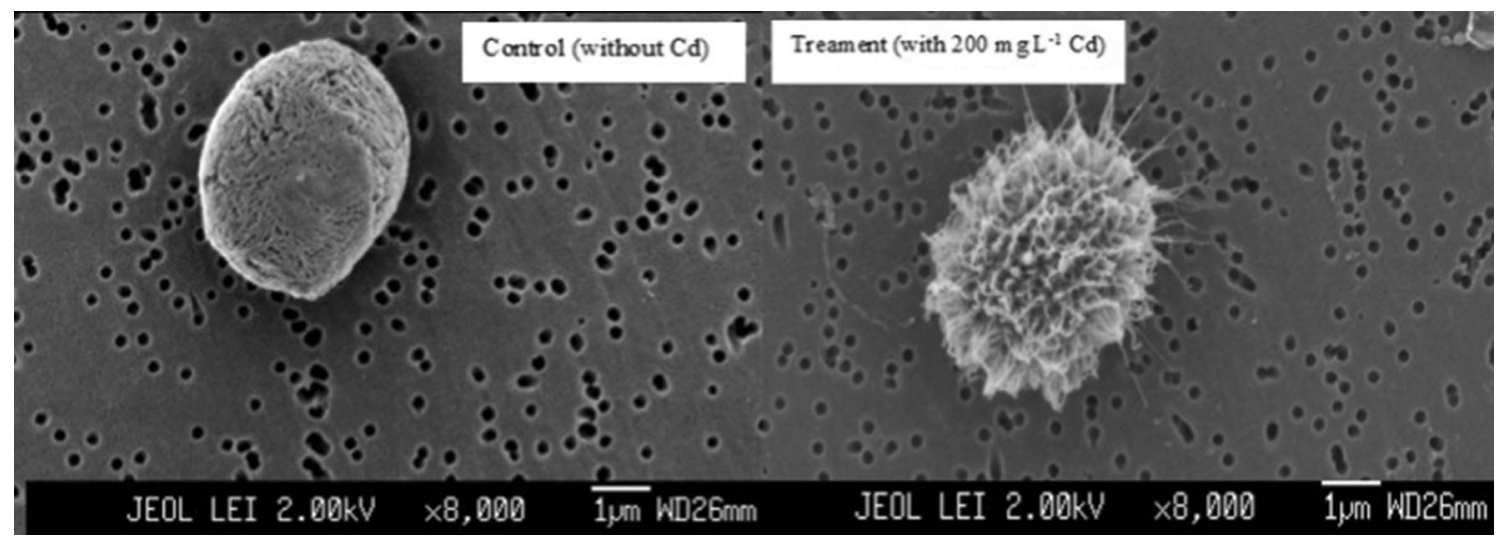

Fig. 1 Effects of cadmium on the morphology of NSE1 


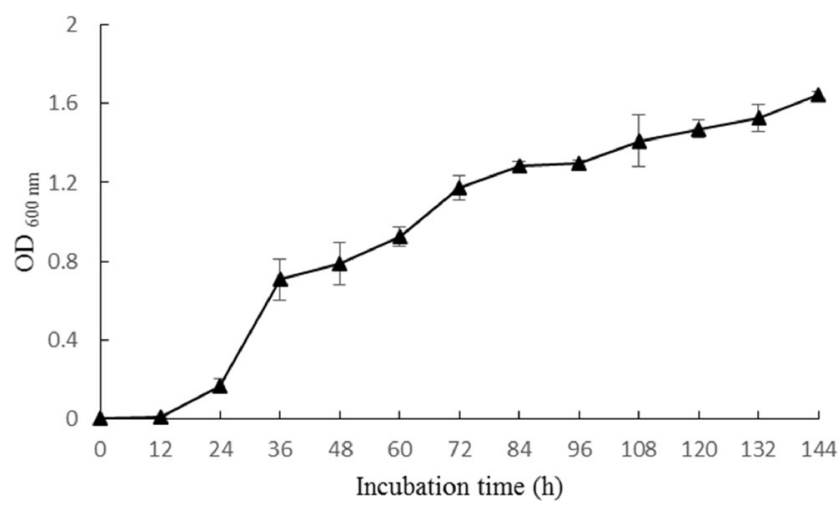

Fig. 3 Growth dynamic of Cryptococcus sp. NSE1 varied with incubation time

(provides information on species richness (Zak et al. 1994)), and Simpson index (which quantifies the number of species as well as the relative abundance of each species (Garland 1996)) showed no significant difference between the inoculated NSE1 and the control by analysis of variance (ANOVA) for microbial community diversity indexes $(p<0.05)$ (Table 3 ). On account of the uncontrollable factors in field trials, the error is large. However, inoculation with NSE1 into the heavy metal-contaminated soil could result in a slight increase in microbial activity and diversity.

\section{Discussion}

In this investigation, Cryptococcus sp. NSE1, a yeast with high Cd resistances $\left(1000 \mathrm{mg} \mathrm{L}^{-1}\right)$ and the ability to utilize ACC as sole nitrogen source, improved phytoremediation by the $\mathrm{Cd}$ hyperaccumulator S. plumbizincicola. NSE1 was also found to be resistant and able to absorb zinc, copper, and cadmium (Table 1). NSE1 formed irregular spines on the cell surface when exposed to $\mathrm{Cd}$, which may provide insight into the yeast mechanism for the absorption of heavy metals. The cell wall of yeast mainly consists of glucan, mannosan, protein, amino glucose, phosphoric acid, and lipoid, with a large number of chemical functional groups containing nitrogen, oxygen, sulfur, and phosphorus, which can adsorb $\mathrm{Cd}^{2+}$ by Van der Waals electrostatic adsorption or covalent binding to depress the toxicity of heavy metals. Therefore, we proposed that the changes

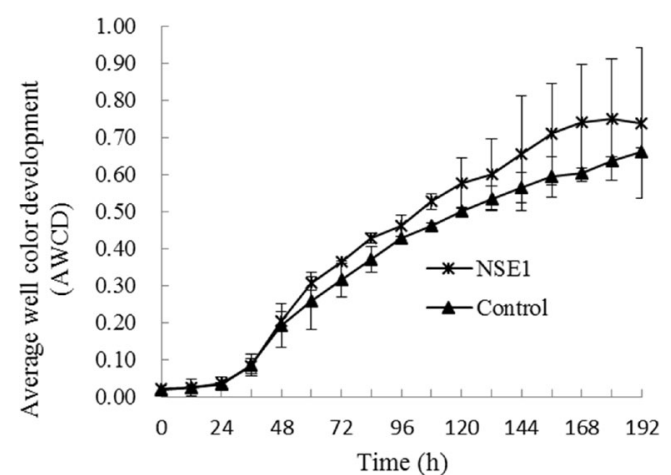

Fig. 4 Variation in average well color development (AWCD) over time in Biolog ECO plates

of morphology could have played a role in the process of adsorption of $\mathrm{Cd}$, due to the chelation and complexation of polysaccharide substances. This mechanism needs to be explored further to provide definite details.

While eukaryotic species, such as Cryptococcus sp., have been shown to assist phytoremediation and possess antifungal activities (Cloete et al. 2009), plant growth promotion has typically been investigated using rhizosphere-associated PGP bacteria. Yeasts possess analogous beneficial bioactivity to PGP bacteria (Agamy et al. 2013) and have to date been relatively under investigated. NSE1 was isolated from the SMN medium containing ACC as a sole carbon source, implying NSE1 is capable of producing ACC deaminase and lowering plant ethylene levels which is similar to the study of Amprayn et al. (2012). P is one of the major essential macronutrients for biological growth and development (Ehrlich 1990). Cryptococcus sp. NSE1 was capable of increasing the availability of dissolved inorganic phosphate (Fig. 2). A large portion of soluble inorganic phosphate, applied to soils as chemical fertilizer, is rapidly immobilized soon after application and is unavailable to plants (Rodriguez and Fraga 1999). PGP strains can exert a positive effect on plant growth through the solubilization of inorganic phosphate and mineralization of organic phosphate, which convert insoluble inorganic $\mathrm{P}$ into a form (e.g., $\mathrm{H}_{2} \mathrm{PO}_{4}{ }^{-}$) usable by plants in acid soils (Lynch 1984). According to the experiment, NSE1 possesses a strong solubilizing ability that can reach $195.2 \mathrm{mg} \mathrm{L}^{-1}$ in the PVK medium (Fig. 2). Within

Table 2 Effects of NSE1 on plant biomass, Cd plant concentration, and extractable Cd soil fractions

\begin{tabular}{|c|c|c|c|c|c|c|}
\hline \multirow[t]{2}{*}{ Treatments } & \multirow{2}{*}{$\begin{array}{l}\text { Dry biomass } \\
\left(\mathrm{g} \mathrm{m}^{-2}\right)\end{array}$} & \multirow{2}{*}{$\begin{array}{l}\text { Concentration in plant } \\
\left(\mathrm{mg} \mathrm{g}^{-1}\right)\end{array}$} & \multirow{2}{*}{$\begin{array}{l}\text { Accumulation of } \mathrm{Cd} \\
\left(\mathrm{mg} \mathrm{m}^{-2}\right)\end{array}$} & \multirow{2}{*}{$\begin{array}{l}\text { Total } \mathrm{Cd} \text { in soil } \\
\left(\mathrm{mg} \mathrm{kg}^{-1}\right)\end{array}$} & \multicolumn{2}{|c|}{ Extractable in soil } \\
\hline & & & & & $\mathrm{HCl}\left(\mathrm{mg} \mathrm{kg}^{-1}\right)$ & $\begin{array}{l}\mathrm{CaCl}_{2} \\
\left(\mathrm{mg} \mathrm{kg}^{-1}\right)\end{array}$ \\
\hline NSE1 & $308 \pm 16 a$ & $0.099 \pm 0.007 \mathrm{a}$ & $31.10 \pm 0.693 \mathrm{a}$ & $0.315 \pm 0.067 \mathrm{a}$ & $0.253 \pm 0.029 \mathrm{a}$ & $0.067 \pm 0.007 \mathrm{a}$ \\
\hline Control & $211 \pm 12 b$ & $0.093 \pm 0.007 \mathrm{a}$ & $19.58 \pm 0.899 b$ & $0.438 \pm 0.075 \mathrm{a}$ & $0.416 \pm 0.028 b$ & $0.095 \pm 0.009 b$ \\
\hline
\end{tabular}

Each treatment contained three replicates. Data were expressed as mean \pm standard error. Different letters are statistically different at $p<0.05$ according to ANOVA (similarly hereinafter) 
Table 3 Effect of NSE1 on microbial diversity indexes in soil

\begin{tabular}{lllll}
\hline Treatments & Shannon-Wiener index & McIntosh index & Richness & Simpson index \\
\hline NSE1 & $2.69 \pm 0.277 \mathrm{a}$ & $5.52 \pm 0.719 \mathrm{a}$ & $24.50 \pm 0.707 \mathrm{a}$ & $0.95 \pm 0.010 \mathrm{a}$ \\
Control & $2.65 \pm 0.322 \mathrm{a}$ & $4.07 \pm 0.450 \mathrm{a}$ & $20.50 \pm 0.7077 \mathrm{~b}$ & $0.95 \pm 0.007 \mathrm{a}$ \\
\hline
\end{tabular}

Different letters are statistically different at $p<0.05$ according to ANOVA these experiments, the $\mathrm{pH}$ value of the solution changed inversely to the concentration of soluble $\mathrm{P}$. The solubilization of $\mathrm{P}$ is commonly associated with a decrease in $\mathrm{pH}$ (Puente et al. 2004) and has been reported in fungi as a result of production of various organic acids, including citric acid, gluconic acid (Reyes et al. 2001; Whitelaw et al. 1999), and oxalic acid (Gharieb 2000). As seen in Fig. 2, soluble $P$ in the solution which rose slowly over time had a peak of $105.4 \mathrm{mg} \mathrm{L}^{-1}$ at $72 \mathrm{~h}$ and was followed by a sudden decrease at $84 \mathrm{~h}$ (40.8 $\mathrm{mg} \mathrm{L}^{-1}$ ). Previously, the phosphate solubilization capacity of the phosphate-solubilizing bacteria has been reported to range from 8 to $233.35 \mathrm{mg} \mathrm{L}^{-1}$ (Nautiyal 1999; Liu et al. 2015a; Yu et al. 2011). NSE1 was able to solubilize $195.2 \mathrm{mg} \mathrm{L}^{-1}$ when cultured for 6 days, placing it at the higher end of this range.

Interestingly, a sudden repeatable decrease occurred at $84 \mathrm{~h}$ during the process of cultivation, accompanied by a slight rise of $\mathrm{pH}$ (Fig. 2). In former studies, Illmer and Schinner (1995), and supported by others (de Freitas et al. 1997), found a similar phenomenon of Penicillium aurantiogriseum and Pseudomonas sp., which they proposed was likely due to the release of protons accompanying respiration or $\mathrm{NH}_{4}{ }^{+}$assimilation as the most probable reason for $\mathrm{P}$ solubilization without acid production. Whitelaw et al. (1999) proposed that fungus Penicillium radicum may consume more $\mathrm{P}$ than it was releasing, resulting in the observed decrease during exponential growth. Therefore, the specific phosphate solubilization mechanism in the soil needs to be further studied.

A number of studies have demonstrated the importance of bacterial inoculation for plant growth and heavy metal accumulation during phytoremediation in heavy metal-polluted environments (Sheng and Xia 2006). NSE1 was able to improve phytoremediation in conjunction with $S$. plumbizincicola when inoculated into contaminated soil in this study. The dry biomass yield of $S$. plumbizincicola (308 $\mathrm{g} \mathrm{m}^{-2}$ ) of treatment (NSE1) was significantly $(p<0.05)$ increased compared with that of the control $\left(211 \mathrm{~g} \mathrm{~m}^{-2}\right)$. However, the concentration of $\mathrm{Cd}$ in the plant biomass showed no significant difference between the control (0.093 $\left.\mathrm{mg} \mathrm{g}^{-1}\right)$ and NSE1 (0.099 $\left.\mathrm{mg} \mathrm{g}^{-1}\right)$. It seems most likely that inoculation of $S$. plumbizincicola with Cryptococcus. sp. NSE1 did not significantly influence the concentrations of $\mathrm{Cd}$ in shoot systems (Table 2) but promoted the growth of plants which consequently increased the total Cd uptake, even under field conditions. Various microbial species have been reported capable of protecting plants against the inhibitory effects of cadmium and improving phytoremediation by increasing plant biomass rather than due to an increase in concentration of cadmium in the root and shoot systems. Dell'Amico et al. (2008) also found the similar phenomenon; the strains did not influence the concentration in the shoots or roots but increased the plant biomass and consequently the total cadmium accumulation. Liu et al. (2015a) found inoculation of NSX2 and LCR1 significantly increased the dry weight of plant shoots other than the $\mathrm{Cd}$ concentrations in shoots. NSE1 may have exhibited beneficial effects in our experiment due to its resistance and adsorption of $\mathrm{Cd}$, as well as PGP abilities including ACC deaminase production and phosphate solubilization abilities, thus protecting the plants against the inhibitory effects of cadmium while promoting the plant growth and increasing the overall uptake of $\mathrm{Cd}$ by increasing the biomass.

Phytoremediation also depends on the activity of the rhizosphere-associated microbial community (Ma et al. 2009). While the function of the microbial community as a whole can enhance the phytoremediation of contaminated soils (Reichman 2007), plants also provide additional surfaces for microbial colonization and organic compounds in root exudates that form a feedback mechanism between the plant and the community (Liu et al. 2015b). The addition of inoculants or an increase in plant growth has the potential to change the community function through changes to this feedback mechanism. Biolog Eco plates were utilized to evaluate qualitatively and quantitatively the community-level physiological profile of the microbial communities in the presence and absence of the NSE1 inoculum. Average well color development (AWCD) was calculated as an indicator of rate of carbon utilization, richness values were calculated as the number of oxidized C substrates, and the Shannon-Weiner index values were calculated using an OD of 0.25 as threshold for positive response. In this present study, the average microbial utilization and microbial diversity was higher in the communities supplemented with NSE1 (Fig. 4 and Table 3). The richness values showed significant difference $(p<0.05)$ between NSE1 and the control. According to Table 3, carbon utilization, metabolic activity, and biological diversity of NSE1 were slightly higher than that of the control treatment. Overall, it appears that the addition of NSE1 may have provided a slight beneficial effect for the microbial community function indirectly through promoting the plant growth or directly by increasing available phosphate while sequestering local $\mathrm{Cd}$. 


\section{Conclusions}

In this study, a Cd-tolerant plant growth-promoting yeast, NSE1, which can also absorb heavy metals, was isolated and identified as Cryptococcus sp. Irregular spines were formed on the surface in the MSM medium containing $200 \mathrm{mg} \mathrm{L}^{-1} \mathrm{Cd}$. The irregular spines are speculated to be polysaccharide substances that may form a $\mathrm{Cd}$ polysaccharide complex reducing Cd bioavailability. NSE1 exhibited plant growth-promoting properties, ACC deaminase, and inorganic phosphate solubilization. We speculate that NSE1 inoculation could alleviate Cd toxicity to the plants and enhance the phytoremediation efficiency of $S$. plumbizincicola in Cd-contaminated soil by increasing biomass. Moreover, the microbial function diversity of inoculated NSE1 was slightly higher than that of the control treatment. This system has the potential to improve the removal efficiency of phytoremediation in a Cd-contaminated area through application of eukaryotic and bacterial inoculums. Further study on the mechanisms is needed.

Acknowledgments We thank the Key Projects in the National Science and Technology Pillar Program (2015BAD05B04) and National High Technology Research and Development Program of China (863 Program) (2012AA06A204) for the financial support.

\section{References}

Agamy R, Hashem M, Alamri S (2013) Effect of soil amendment with yeasts as bio-fertilizers on the growth and productivity of sugar beet. Afr J Agric Res 8:46-56

Alonso LM, Kleiner D, Ortega E (2008) Spores of the mycorrhizal fungus Glomus mosseae host yeasts that solubilize phosphate and accumulate polyphosphates. Mycorrhiza 18:197-204

Amprayn KO, Rose MT, Kecskés M, Pereg L, Nguyen HT, Kennedy IR (2012) Plant growth promoting characteristics of soil yeast (Candida tropicalis $\mathrm{HY}$ ) and its effectiveness for promoting rice growth. Appl Soil Ecol 61:295-299

Bankar AV, Zinjarde SS, Kapadnis BP (2012) "Management of heavy metal pollution by using yeast biomass," in Microorganisms in Environmental Management, Springer, Berlin, pp. 335-363

Belimov AA, Safronova VI, Sergeyeva TA, Egorova TN, Matveyeva VA, Tsyganov VE, Borisov AY, Tikhonovich IA, Kluge C, Preisfeld A, Dietz KJ, Stepanok VV (2001) Characterization of plant growth promoting rhizobacteria isolated from polluted soils and containing 1-aminocyclopropane-1-carboxylate deaminase. Can J Microbiol 47:642-652

Botha A (2011) The importance and ecology of yeasts in soil. Soil Biol Biochem 43:1-8

Bundy JG, Paton GI, Campbell CD (2004) Combined microbial community level and single species biosensor responses to monitor recovery of oil polluted soil. Soil Biol Biochem 36:1149-1159

Chen L-A, Luo S-L, Xiao X-A, Guo H-J, Chen J-L, Wan Y, Li B, Xu T-Y, Xi Q-A, Rao C, Liu C-B, Zeng G-M (2010) Application of plant growth-promoting endophytes (PGPE) isolated from Solanum nigrum L. For phytoextraction of Cd-polluted soils. Appl Soil Ecol 46:383-389
Cheng H-R, Jiang N (2006) Extremely rapid extraction of DNA from bacteria and yeasts. Biotechnol Lett 28:55-59

Cloete KJ, Valentine AJ, Stander MA, Blomerus LM, Botha A (2009) Evidence of symbiosis between the soil yeast Cryptococcus laurentii and a sclerophyllous medicinal shrub, Agathosma betulina (berg.) pillans. Microb Ecol 57:624-632

Dell'Amico E, Cavalca L, Andreoni V (2008) Improvement of Brassica napus growth under cadmium stress by cadmium-resistant rhizobacteria. Soil Biol Biochem 40:74-84

De Freitas JR, Banerjee MR, Germida JJ (1997) Phosphate-solubilizing rhizobacteria enhance the growth and yield but not phosphorus uptake of canola (Brassica napus L). Biol Fertil Soils 24:358-364

Ehrlich HL (1990) Geomicrobial applications to bioremediation-foreword. Geomicrobiol J 8:R5-R5

El-Tarabily KA, Sivasithamparam K (2006) Potential of yeasts as biocontrol agents of soil-borne fungal plant pathogens and as plant growth promoters. Mycoscience 47:25-35

Falih AM, Wainwright M (1995) Nitrification, s-oxidation and psolubilization by the soil yeast Williopsis californica and by Saccharomyces cerevisiae. Mycol Res 99:200-204

Garland JL (1996) Analytical approaches to the characterization of samples of microbial communities using patterns of potential C source utilization. Soil Biol Biochem 28:213-221

Garland JL (1997) Analysis and interpretation of community-level physiological profiles in microbial ecology. FEMS Microbiol Ecol 24: 289-300

Garland JL, Mills AL (1991) Classification and characterization of heterotrophic microbial communities on the basis of patterns of community-level sole-carbon-source utilization. Appl Environ Microbiol 57:2351-2359

Gharieb MM (2000) Nutritional effects on oxalic acid production and solubilization of gypsum by Aspergillus niger. Mycol Res 104: $550-556$

Gomez E, Ferreras L, Toresani S (2006) Soil bacterial functional diversity as influenced by organic amendment application. Bioresour Technol 97:1484-1489

Guo H-J, Luo S-L, Chen L-A, Xiao X, Xi Q-A, Wei W-Z, Zeng G-M, Liu C-B, Wan Y, Chen J-L, He Y-J (2010) Bioremediation of heavy metals by growing hyperaccumulaor endophytic bacterium Bacillus sp. L14. Bioresour Technol 101:8599-8605

Illmer P, Schinner F (1995) Solubilization of inorganic calcium phosphates-solubilization mechanisms. Soil Biol Biochem 27:257263

Jiang C-Y, Sheng X-F, Qian M, Wang Q-Y (2008) Isolation and characterization of a heavy metal-resistant Burkholderia sp. from heavy metal-contaminated paddy field soil and its potential in promoting plant growth and heavy metal accumulation in metal-polluted soil. Chemosphere 72:157-164

Johansson JF, Paul LR, Finlay RD (2004) Microbial interactions in the mycorrhizosphere and their significance for sustainable agriculture. FEMS Microbiol Ecol 48:1-13

Kloepper JW, Schroth MN, Miller TD (1980) Effects of rhizosphere colonization by plant growth-promoting rhizobacteria on potato plant development and yield. Phytopathology 70:1078-1082

Kumar R, Das AJ, Juwarkar AA (2015) Reclamation of petrol oil contaminated soil by rhamnolipids producing PGPR strains for growing Withania somnifera a medicinal shrub. World J Microbiol Biotechnol 31:307-313

Kurtzman CP, Robnett CJ (1997) Identification of clinically important ascomycetous yeasts based on nucleotide divergence in the $5^{\prime}$ end of the large-subunit (26S) ribosomal DNA gene. J Clin Microbiol 35:1216-1223

Liu W-X, Wang Q-L, Wang B-B, Hou J-Y, Luo Y-M, Tang C-X, Franks AE (2015a) Plant growth-promoting rhizobacteria enhance the growth and Cd uptake of Sedum plumbizincicola in a Cdcontaminated soil. J Soils Sediments 15:1191-1199 
Liu Z-F, Ge H-G, Li C, Zhao Z-P, Song F-M, Hu S-B (2015b) Enhanced phytoextraction of heavy metals from contaminated soil by plant cocropping associated with PGPR. Water Air Soil Pollut 226:10

Lu R-K (1999) Analytical methods of soil agricultural chemistry. Analytical Methods of Soil Agricultural Chemistry, Beijing (in Chinese)

Lynch JM (1984) Advances in agricultural microbiology - NS Subba-Rao (editor). Agric Ecosyst Environ 11:90-92

Ma Y, Rajkumar M, Freitas H (2009) Isolation and characterization of Ni mobilizing PGPB from serpentine soils and their potential in promoting plant growth and $\mathrm{Ni}$ accumulation by Brassica spp. Chemosphere 75:719-725

Malik A, Jaiswal R (2000) Metal resistance in pseudomonas strains isolated from soil treated with industrial wastewater. World J Microbiol Biotechnol 16:177-182

Marques A, Moreira H, Franco AR, Rangel A, Castro PML (2013) Inoculating Helianthus annuus (sunflower) grown in zinc and cadmium contaminated soils with plant growth promoting bacteriaeffects on phytoremediation strategies. Chemosphere 92:74-83

Mukherjee S, Sen SK (2015) Exploration of novel rhizospheric yeast isolate as fertilizing soil inoculant for improvement of maize cultivation. J Sci Food Agric 95:1491-1499

Nassar AH, El-Tarabily KA, Sivasithamparam K (2005) Promotion of plant growth by an auxin-producing isolate of the yeast Williopsis saturnus endophytic in maize (Zea mays L.) roots. Biol Fertil Soils 42:97-108

Payne SM (1994) Detection, isolation, and characterization of siderophores. Bact Pathog Pt A 235:329-344

Puente ME, Bashan Y, Li C-Y, Lebsky VK (2004) Microbial populations and activities in the rhizoplane of rock-weathering desert plants. I. Root colonization and weathering of igneous rocks. Plant Biol 6:629-642

Reichman SM (2007) The potential use of the legume-rhizoblum symbiosis for the remediation of arsenic contaminated sites. Soil Biol Biochem 39:2587-2593

Reyes I, Baziramakenga R, Bernier L, Antoun H (2001) Solubilization of phosphate rocks and minerals by a wild-type strain and two UVinduced mutants of Penicillium rugulosum. Soil Biol Biochem 33: $1741-1747$

Rodriguez H, Fraga R (1999) Phosphate solubilizing bacteria and their role in plant growth promotion. Biotechnol Adv 17:319-339

Sambrook JR, Russell DW (2001) Molecular cloning - a laboratory manual. Cold Spring Harbor Laboratory Press, New York

Sandalio LM, Dalurzo HC, Gomez M, Romero-Puertas MC, del Rio LA (2001) Cadmium-induced changes in the growth and oxidative metabolism of pea plants. J Exp Bot 52:2115-2126
Sansone G, Rezza I, Calvente V, Benuzzi D, de Tosetti MIS (2005) Control of Botrytis Cinerea strains resistant to iprodione in apple with rhodotorulic acid and yeasts. Postharvest Biol Technol 35:245251

Sato A, Takeda H, Oyanagi W, Nishihara E, Murakami M (2010) Reduction of cadmium uptake in spinach (Spinacia oleracea L.) by soil amendment with animal waste compost. J Hazard Mater 181:298-304

Nautiyal CS (1999) An efficient microbiological growth medium for screening phosphate solubilizing microorganisms. FEMS Microbiol Lett 170:265-270

Sheng XF, Xia JJ (2006) Improvement of rape (Brassica napus) plant growth and cadmium uptake by cadmium-resistant bacteria. Chemosphere 64:1036-1042

Staniszewska M, Bondaryk M, Swoboda-Kopec E, Siennicka K, Sygitowicz G, Kurzatkowski W (2013) Candida albicans morphologies revealed by scanning electron microscopy analysis. Braz $\mathrm{J}$ Microbiol 44:813-821

Spellerberg IF, Fedor PJ (2003) A tribute to Claude Shannon (1916-2001) and a plea for more rigorous use of species richness, species diversity and the 'Shannon-Wiener' index. Glob Ecol Biogeogr 12:177179

Vessey JK (2003) Plant growth promoting rhizobacteria as biofertilizers. Plant Soil 255:571-586

Whitelaw MA, Harden TJ, Helyar KR (1999) Phosphate solubilisation in solution culture by the soil fungus Penicillium radicum. Soil Biol Biochem 31:655-665

Wu L-H, Li N, Luo Y-M (2008) Phytoextraction of heavy metal contaminated soil by Sedum plumbizincicola under different agronomic strategies. Proceedings of the 5th International Phytotechnology Conference, pp 49-50

Yin Z, Cao J, Li Z, Qiu D (2015) Reducing the bioavailability of cadmium in contaminated soil by dithiocarbamate chitosan as a new remediation. Environ Sci Pollut Res 22:9668-9675

Yu X, Liu X, Zhu T-H, Liu G-H, Mao C (2011) Isolation and characterization of phosphate-solubilizing bacteria from walnut and their effect on growth and phosphorus mobilization. Biol Fertil Soils 47: $437-446$

Zak J-C, Willig M-R, Moorhead D-L, Wildman H-G (1994) Functional diversity of microbial communities - a quantitative approach. Soil Biol Biochem 26:1101-1108

Żukowska J, Biziuk M (2008) Methodological evaluation of method for dietary heavy metal intake. J Food Sci 73:R21-R29 